\title{
Geoecological aspects of stress-strain state modeling results of Leninsky coal deposit (Kuzbass, Russia)
}

\author{
A. I. Manevich ${ }^{1,2}$, K. S. Kolikov², and E. A. Egorova ${ }^{2}$
}

Received 27 September 2018; accepted 3 April 2019; published 16 July 2019.

This paper describes the analysis of numerical simulation results of the stress-strain state of Leninsky coal deposit area (Kuzbass) before and after allotment mining of mining fields specified in this article. The analysis of the influence of coal mining on the stress-strain state of rocks is performed taking into account the fault tectonics of the area. The particularities of the influence of regional stress field changes on geoecological safety are considered. The geoecological consequences of the exploitation of coal seams of the Leninsky coal deposit were analyzed. KEYWORDS: Leninsky coal deposit; mine; Kuzbass; modeling; stress-strain state; coal mining.

Citation: Manevich, A. I., K. S. Kolikov, and E. A. Egorova (2019), Geoecological aspects of stress-strain state modeling results of Leninsky coal deposit (Kuzbass, Russia), Russ. J. Earth. Sci., 19, ES4002, doi:10.2205/2019ES000663.

\section{Introduction}

Leninsky coal deposit geographically belongs to the North-Western part of the Kuznetsk coal basin, inclining to the Kuznetsk's Alatau. The Kuznetsk coal basin itself is a large synclinorium, which has the shape of an irregular quadrangle in the plan, the long axis of which is oriented in the NW-SE direction [Nedra, 1967]. In geomorphological terms, the region is an intermountain basin. It is bounded on the east by the Kuznetsk Alatau, on the south by mountain Shoria, and on the south-west and west by Salair. Against the background of AltaiSayan folded region, represents a set of mountain ranges, clearly expressed in relief in the form of mountain ranges [Nedra, 1967. Modern geodynamic activity is expressed in the growth of new elevations due to the reduction of depressions resulted from the general uplift of the territory [Panina and Zaitsev, 2012. This is confirmed by geo-

\footnotetext{
${ }^{1}$ Geophysical Center RAS, Moscow, Russia

${ }^{2}$ Mining Institute of NUST "MISiS", Moscow, Russia
}

Copyright 2019 by the Geophysical Center RAS. http://rjes.wdcb.ru/doi/2019ES000663-res.html morphological data, by the results of re-leveling, by observations using global navigation satellite systems (GNSS), as well as by spontaneous gas emission in the territory of the Leninsky coal deposit (LCD) [Batugina and Petukhov, 1988; Kartashev and Yesikov, 1983, Novikov et al., 2013, Panina and Zaitsev, 2012.

A large amount of geological, tectonic and seismological data about the state of this area has been accumulated over the long period of LCD operation [Adushkin, 2015. Emanov, 2009, Lazarevich and Polyakov, 2009, Novikov et al., 2013. Panina and Zaitsev, 2012, Yakovlev et al., 2013. Large-scale mining operations cause massive anthropogenic changes in the geological environment, which lead to a negative impact on the geological environment, water objects, the ground surface and the biosphere. In this regard, the research of the stress-strain state of the Kuzbass areas is of particular relevance. And in this paper additional data are presented that could be useful in the geoecologycal assessment of the area.

This paper aims to analyze the stress-strain state of the area of the LCD. For this, the SSS of a fragment of the geological environment of the studied area was modeled. In our work, 
we used the map of fault tectonics of Central Kuzbass [Novikov et al., 2013. Yakovlev et al., 2013 with drawn planned mine fields (Database of State Geological Maps, All-Russian Scientific Research Geological Institute named A. P. Karpinsky of the RAS, Electronic resource, URL: http://webmapget.vsegei.ru/index.html, reference date: 10.09.2018) as a geometric model. To determine the tectonic component of stresses, we used the data on the direction of the axes of the main tectonic stresses. The data was based on the results of morphotectonic studies of the Kuznetsk basin [Novikov et al., 2013, Panina and Zaitsev, 2012.

The modeling of the stress-strain state of LCD is made using the calculation method of stress-strain state of heterogeneous block arrays with system of tectonic faults. In this case the fault refers to the volumetric area of the dispersion of rocks with an elastic modulus significantly lower than in the surrounding rocks [Morozov et al., 2012, 2018.

\section{Structural and Tectonic Model of Leninsky Coal Deposit}

From geological point of view, LCD is located in complicated tectonic conditions. The coal seams of this deposit are formed by Leninskaya syncline, which is a wide fold with asymmetric wings and mildly sloping downfold. The syncline downfold is sinking from the Central part of the field to the North-West $\left(2-3^{\circ}\right)$ and South-East $\left(3-5^{\circ}\right)$. The South-Western wing of the fold is complicated by Leninskaya anticline with the angle of inclination of wings varying from 20 to $40^{\circ}$ [Popov, 1976].

The area of Leninsky coal deposit, as per the results of morphotectonic studies [Novikov et al., 2013 refers to the boundary between two neotectonic blocks of the Prisalair and Kemerovo subdistricts. Usually, there is no exposure of the latest disturbance zones, since they are covered by the deluvial aprons of piedmont foothills in case of differentiated movements along them or by alluvial sediments. This is only possible if there are no significant vertical movements [Novikov et al., 2013]. The thickness of covering complex is from 20 to $40 \mathrm{~m}$ [Novikov et al., 2013]. The heights of neighbour neotectonic blocks within the modelling area are comparable and differ by $20-30 \mathrm{~m}$ [Novikov et al., 2013; Panina and Zaitsev, 2012.

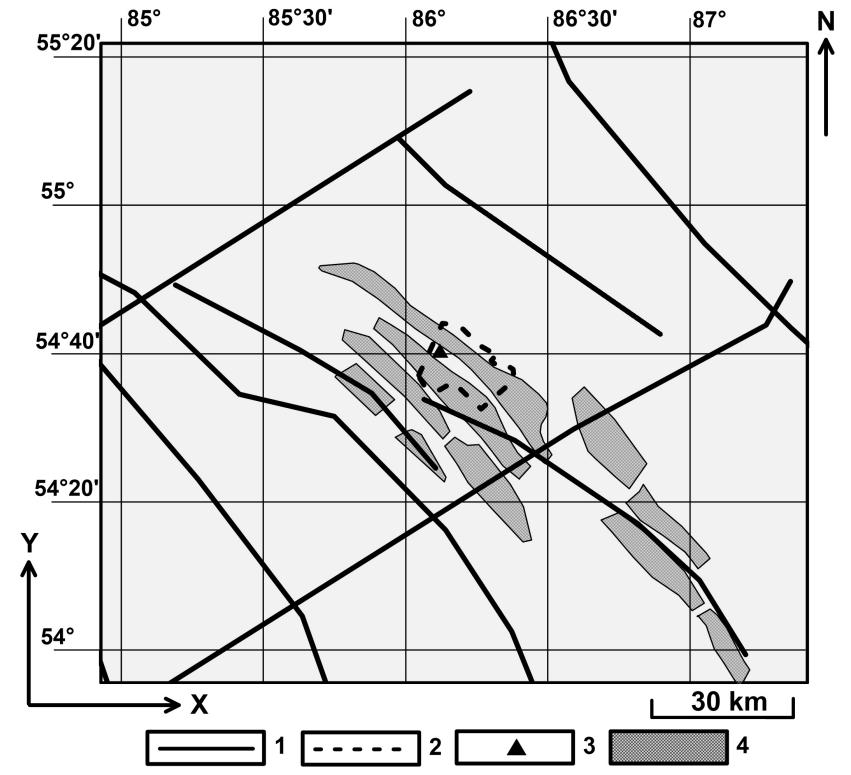

Figure 1. Scheme of fault tectonics of the Leninsky coal deposit based on data of [Lazarevich and Polyakov, 2009, Novikov et al., 2013 Yakovlev et al., 2013] and borders of main mine fields (Database of State Geological Maps, All-Russian Scientific Research Geological Institute named A. P. Karpinsky of the RAS, Electronic resource, URL: http://webmapget.vsegei.ru/index.html, reference date: 10.09.2018): 1 - tectonic faults; 2 - agglomeration of Leninsk-Kuznetsky city; 3 - LeninskKuznetsky city; 4 - mine fields of LCD scheduled to mining, which refer to the area of the supposed dispersion of rocks.

Thus, the structural-tectonic scheme of tectonic fault was used to simulate the stress-strain state (SSS) of the Leninsky coal deposit area (Figure 1), which was verified by geophysical studies, the results of which are presented in [Lazarevich and Polyakov, 2009, Novikov et al., 2013, Yakovlev et al., 2013. The SSS of a fragment of the geological environment of $150 \times 140 \mathrm{~km}$ was simulated. The depth of the simulated layer corresponds to the depth of the mine fields planned for the development (or already developed) and is within 500 $1000 \mathrm{~m}$ from the ground surface. The simulated layer is composed of elastic and fragile rocks: coal, mudstone, siltstone and sandstone. Within the framework of the elastic formulation of the problem, the model of SSS of an elastic isotropic layer with Young's modulus $E=8 \times 10^{3} \mathrm{MPa}$ disturbed by a system of tectonic faults with Young's modu- 
lus lower by two orders and the total Poisson's ratio $\mu=0.25$ is simulated [Geoinformark, 2003, Morozov et al., 2018. We assumed physical and mechanical parameters of the model tentatively, based on the fact that the simulation results are aimed to obtain qualitative rather than quantitative estimates of SSS of the area.

The fault in the model corresponds to mechanically dispersed environment with the width of the fracture zone up to $500 \mathrm{~m}$ [Morozov et al., 2012]. The dip of fault was assumed as vertical at interval depth of intensive mining works. The external field of tectonic stresses is specified by the dominant compression stress $\sigma_{y y}$ with the submeridional orientation axis, which is consistent with the materials of morphotectonic [ Novikov et al., 2013, Panina and Zaitsev, 2012 and seismological [Emanov, 2009: Ovsyuchenko et al., 2010, Zhalkovsky et al., 1995 research.

The model of the block diagram after mining of fields is as follows. The boundaries of the main mine fields planned for mining and located in the range of 500-1000 $\mathrm{m}$ from the ground surface (Database of State Geological Maps, All-Russian Scientific Research Geological Institute named A. P. Karpinsky of the RAS, Electronic resource, URL: http://webmapget.vsegei.ru/index.html, reference date: 10.09.2018) were drawn on the scheme of fault tectonics. Excavation, drive working and all large-scale underground mining within the boundaries of mine fields in general form the volume of dispersed rocks. First of all, this is due to the technology of coal face operations. LCD used the rock pressure control by the complete collapse of the roof of coal seams. Excavation of coal seams at different depths with the collapse of the roof rocks causes the appearance of large zones, with reduced physical and mechanical properties in comparison with the host rocks [Batugin et al., 2016 , Bykadorov et al., 2018. Tarasenko et al., 2017. This is due to the physical appearance of voids and the filling of these voids with water.

We analyzed fields of the stress tensor components $\sigma_{x x}, \sigma_{y y}, \tau_{x y}$ and fields of the stress intensity $\sigma_{i}$. Region includes mine fields of Leninsky coal deposit and agglomeration of Leninsk-Kuznetsky city before and after mining of the fields.

\section{Method of Stress-Strain State Modeling}

In this study we used the methodology and software to calculate stress-strain state of block heterogeneous massifs disturbed by a system of tectonic faults in the external field of tectonic stresses [Morozov et al., 2012, 2018. The medium inside the study area is isotropic-elastic, disturbed by the system of tectonic faults and zones of mined out areas.

In modelling process, the fault and zones of worked-out coal seams correspond to isotropicelastic medium with a modulus of elasticity twice lower than elastic modulus of hosting rocks.

The stress-strain state in the massif is calculated by the finite element method as displacements based on four-square isoparametric elements. [Morozov et al., 2012. The choice of the finite element method as a calculation approach stems from physical considerations that yield conditions for minimizing the total potential strain energy throughout the massif; the efficiency of mathematical calculations is also a factor.

The relations between stresses and strains are taken according to the generalized Hooke elasticity law [Baklashov, 2004]:

$$
\sigma_{i j}=D_{i j} \times \varepsilon_{i j}
$$

where $\sigma_{i j}$ are the components of the stress tensor:

$$
\sigma_{i j}=\left\{\begin{array}{ll}
\sigma_{x x} & \tau_{x y} \\
\tau_{x y} & \sigma_{y y}
\end{array}\right\}
$$

$\varepsilon_{i j}$ are the components of elastic strain tensor:

$$
\varepsilon_{i j}=\left\{\begin{array}{cc}
\varepsilon_{x x} & 0.5 \varepsilon_{x y} \\
0.5 \varepsilon_{x y} & \varepsilon_{y y}
\end{array}\right\}
$$

$D(\mu, E)$ is the matrix of elastic coefficients for isotropic-elastic material. Where $\mu$ is Poisson's ratio; $E$ is Young's modulus, MPa.

The stress intensity is calculated by the following formula (1) [Baklashov, 2004]:

$$
\sigma_{i}=\left(\sigma_{x x}^{2}+\sigma_{y y}^{2}-\sigma_{x x} \times \sigma_{y y}+3 \times \sigma_{x y}^{2}\right)^{1 / 2}
$$

The change of SSS of the studied area is analysed by the magnitude of difference of stress intensity before and after mining of fields:

$$
\Delta \sigma_{i}=\left\langle\sigma_{i}\right\rangle_{I}-\left\langle\sigma_{i}\right\rangle_{I I}
$$




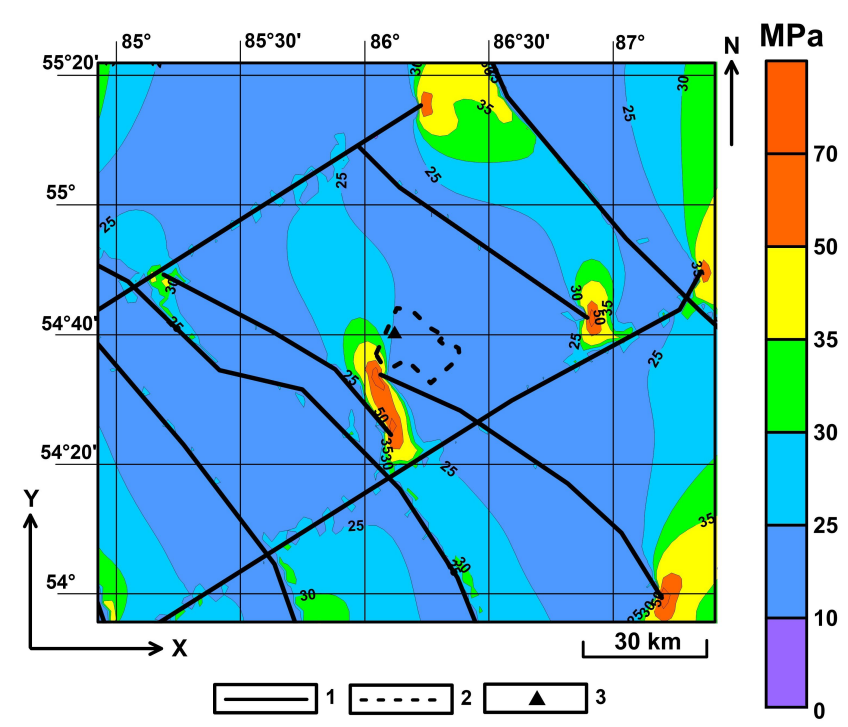

Figure 2. Map of stress intensity $\sigma_{i}$ prior to the mining of fields: 1 - tectonic faults; 2 - agglomeration of Leninsk-Kuznetsky city; 3 - LeninskKuznetsky city.

where $\left\langle\sigma_{i}\right\rangle_{I}$ and $\left\langle\sigma_{i}\right\rangle_{I I}$ is the intensity of stresses at an arbitrary point before and after mining, respectively.

To model the geological massif SSS in the coordinate system $y, x$ (coinciding with the direction North-South and West-East), we establish the conditions of the external field of tectonic stresses. We used stress values $\sigma_{x x}=10 \mathrm{MPa}$ and $\sigma_{y y}=$ $30 \mathrm{MPa}$ based on the different results of measurements of the main stresses of the Earth's crust in various regions [Selin, 2008, Zubkov, 2016]. The selected ratio includes the horizontal tectonic component and the lateral repulse stress of vertical stresses $\sigma_{z z}$.

\section{Results of Numerical Simulation of SSS of LCD}

Figure 2 represents the map of the LCD stress intensity before the mining works. Background values $\sigma_{i}$ in initial massif are in the range of 10-20 MPa. Near the agglomeration of LeninskKuznetsky city and Leninsky deposit, the zone of increased stress intensity $>35 \mathrm{MPa}$ elongated in the NNE orientation is distinguished. One of the coal mine fields belong to this zone.

Figure 3 shows map of the shear stress $\left(\tau_{x y}\right)$. The

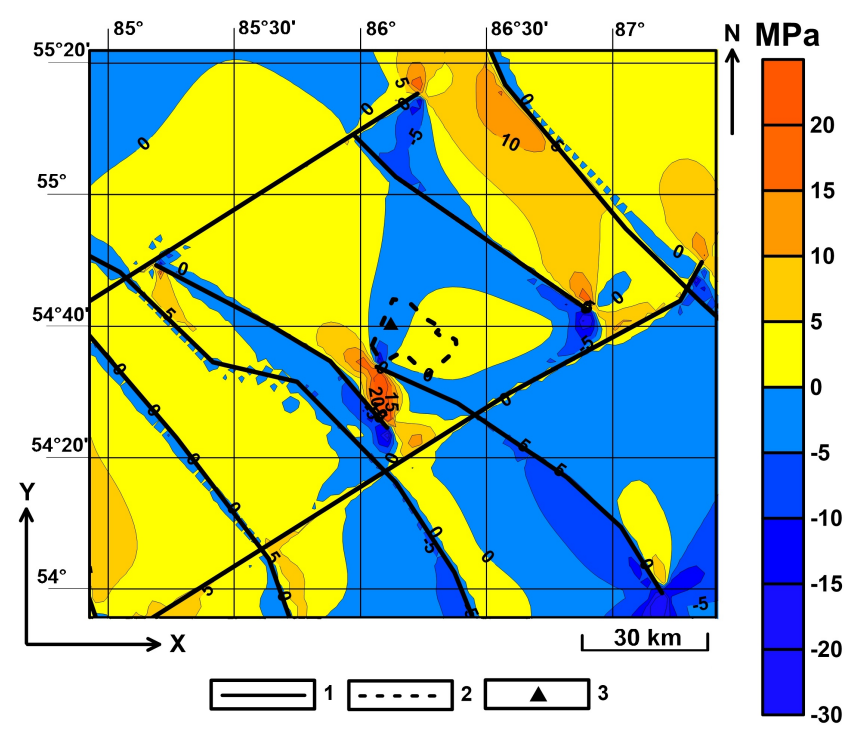

Figure 3. The map of shear stress $\tau_{x y}$ prior to the mining of fields: 1 - tectonic faults; 2 - agglomeration of Leninsk-Kuznetsky city; 3 - LeninskKuznetsky city.

studied area contains the zone of increased shear stresses. The size and orientation of this zone corresponds to the zone of increased stress intensity. The background values of the shear stresses $\tau_{x y}$ in the study area are in the range of $\pm 5 \mathrm{MPa}$

At the next iteration, the SSS of the studied area was calculated for the case when all the planned mine fields in the simulated depth range of 500 $100 \mathrm{~m}$ are worked out. Figure 4 and Figure 5 show maps of stress intensity and shear stresses.

After the end of coal face operations in the area of city agglomeration of Leninsk-Kuznetsky and Leninsky deposit, the area with increased stress Figure 4 and Figure 5 is significantly expanded in the North-West and South-East direction, covering an area of about 2.5 times more before the mining works in the fields. Also, a new area with increased value of stress intensity and shear stress at the end of the mine field in the South-East direction is being formed; this area is currently being worked by two mines: mine named after Kirov and mine "Polysaevskaya".

Figure 6 shows the map of the stress intensity difference $\Delta \sigma_{i}$ calculated by using the formula (2).

The range of released stress intensity $0-5 \mathrm{MPa}$ occupies a significant area and refers to the background. The maximum values of the stress intensity difference $\Delta \sigma_{i}$ reach $15-20 \mathrm{MPa}$. Mining works form areas with high stress intensity which refer to 


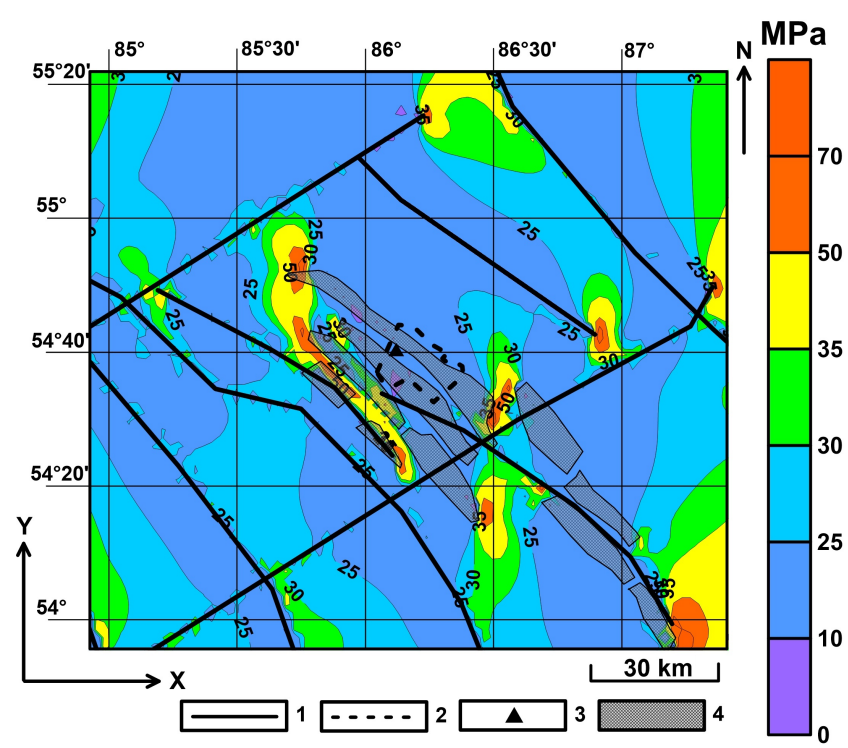

Figure 4. Map of stress intensity $\sigma_{i}$ after mining of fields: 1 - tectonic faults; 2 - agglomeration of Leninsk-Kuznetsky city; 3 - Leninsk-Kuznetsky city; 4 - mine fields of LCD scheduled to mining which refer to the area of the supposed dispersion of rocks.

zones of increased energy saturation.

It should be noted that there is uncertainty in the interpretation of the simulation results. During the long period of deposit coal mining the stress relaxation may occur. This relaxation is caused by the induced seismic phenomena and stress redistribution as a result of slow movements.

\section{Geoecological Aspects of Simulation Results}

Analysis of the results of SSS modelling based on the system approach [Gvishiani et al.,2018] showed that prior to the mining works in the area there was a local zone with heterogeneity of stress fields in the massif. This zone is located between the endings of two tectonic structures limiting the Leninskaya anticline from the Eastern side and oriented to the NNE direction. Then, during the process of development of mining and working-out of coal-bearing seams of LCD, new zones of local heterogeneity of stress field are formed. These zones are confined to the places of dispersion of the geological environment arising from the mining of coal seams. The area of LCD, at the time of mining, includes three

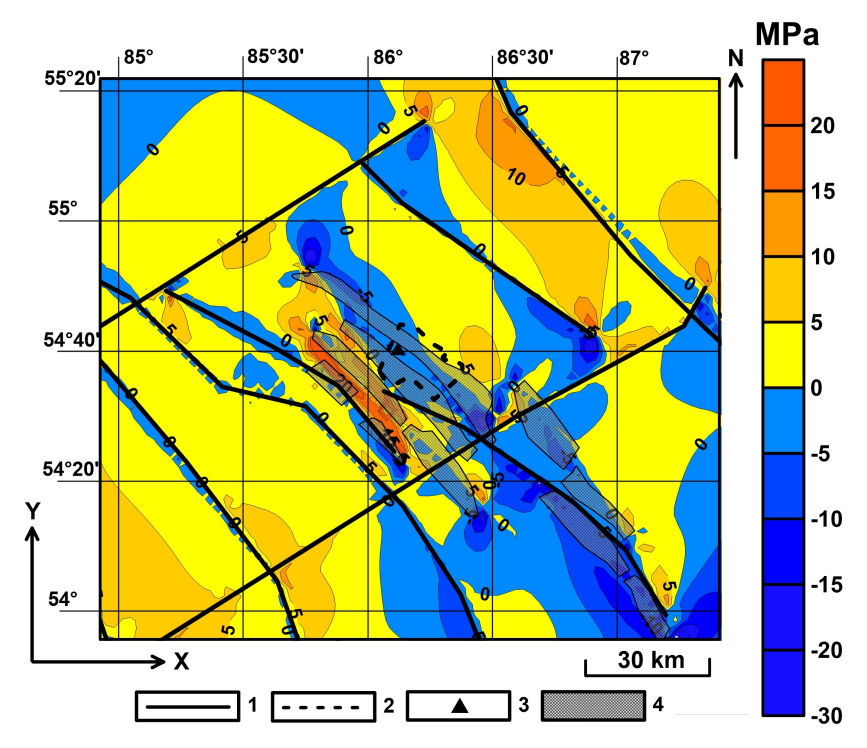

Figure 5. The map of shear stress $\tau_{x y}$ after mining of fields: 1 - tectonic faults; 2 - the agglomeration of Leninsk-Kuznetsky city; 3 - Leninsk-Kuznetsky city; 4 - mine fields of LCD scheduled to mining which refer to the area of the supposed dispersion of rocks.

zones of significantly changed stress intensity. The regions of negative values limiting the region from the West and the East indicate the increased energy saturation of the hosting medium, and the region with positive values $\Delta \sigma_{i}$ indicates the reduced energy saturation. The alternation of such zones at one geological formation can induce the realization of the energy of potential deformations, and serve as a trigger effect for the dynamic events of the host rock mass [Adushkin, 2015; Emanov et al., 2018. Petukhov and Batugina, 1999.

According to the latest data, the problems of safety assessment of mining operations in underground coal mining do not lose their relevance [Batugin, 2018, Litvinov et al., 2017]. The processes of methane release and the formation of conditions for the occurrence of gas-dynamic phenomena in the coal massif is caused by several factors [Kolikov et al., 2016, Litvinov et al., 2017]: a) the increase of the depth of mining operations and the rate of coal seams mining (the rate of advance of the working face), the complication of mining and geological conditions significantly affect the processes of methane release and the formation of conditions for the occurrence of gas-dynamic phenomena in the coal massif. The developed models of the stress-strain state of the LCD area can be used 


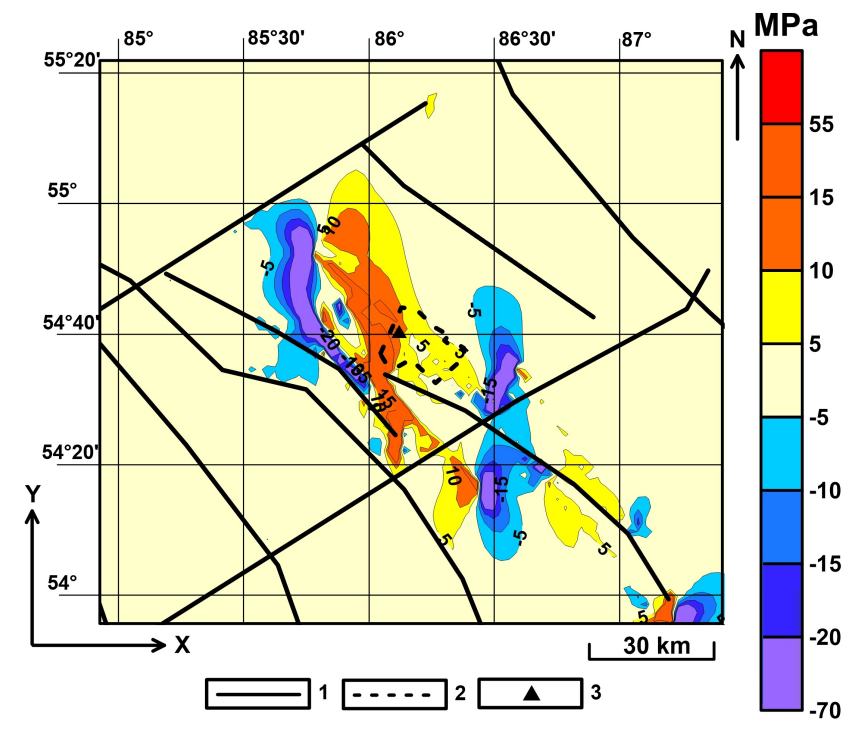

Figure 6. The difference between the stress intensity $\Delta \sigma_{i}$ before and after mining of fields: $1-$ tectonic faults; 2 - the agglomeration of LeninskKuznetsky city; 3 - Leninsk-Kuznetsky city.

as boundary conditions for bigger scale models. A small-scale study of the SSS of the coal massif is necessary for qualitative assessment of changes in the relative permeability of the coal massif, and further search for potentially dangerous zones of formation of gas-dynamic phenomena [Kolikov et al., 2017; Petukhov and Batugina, 1999.

The stress state can have a significant impact on geo-ecological safety at the liquidation of mines and reclamation of district. In the study [Morozov et al., 2012 it was shown that the release of stress contributes to the flow of water fluids from the more intense surrounding massifs into the weakened zone, thereby forming a horizontal gradient of the filtration. Leninsky coal deposit is crossed almost in the middle by the river Inya, which belongs to the III category under the conditions of safety of mining operations under water objects. The third group includes water objects that intersect in the mined areas with geological disturbances, or where the working occurs [Gosgortechnadzor, 1998. Inya River is located in the area of Leninskaya syncline. The safety depth of mining under this river is $200 \mathrm{~m}$, according to the calculation for the objects of category III [Gosgortechnadzor, 1998.

The change of the hydrological regime is an environmental hazard factor. The change in the level of groundwater, the creation of depression craters or dewatering in rivers, lakes and other open water bodies can lead to flooding of the ground surface, to settling of the ground surface and to climate change. The mechanism activating the displacement of the Earth surface after the end of mining works (in the liquidation step) has also another nature. It is due to the decrease in the strength properties of wet rocks during the flooding of worked out area by mine water [Batugin and Klimanova, 2000 .

During the coal seams excavation the technology of roof fall is used. The filling of worked out area by water may occur due to the drainage of the water horizons entering into the zone of water-conducting fractures. Therefore, the large inflows are possible not only under the river or floodplain, but also at a considerable distance from them. In a number of cases mentioned in [Gvirtsman et al., 1977], there was no increase in the inflow of water into the mine workings and there were no records about formation of cracks on the ground surface extending under the waterbody. It follows that with sufficient depth of mining, the cracks that are forming on the ground surface, do not communicate with the zone of water-conducted cracks over the workedout space.

However, the presence of hydraulic connection of the Inya River and some layers of LCD can be estimated. The following cases of increases of inflows into the mined-out space were recorded at undermining of flood-lands of Inya River [Gvirtsman et al., 1977:

- Boldyrevsky seam, the depth of the working is $150 \mathrm{~m}$, the increase of the inflow was $40 \mathrm{~m}^{3} / \mathrm{h}$;

- Tomachevsky seam, the depth of the working is $20-120 \mathrm{~m}$, the increase in the inflow was $100 \mathrm{~m}^{3} / \mathrm{h}$;

- Polenor seam, the depth of the working is 120-200 $\mathrm{m}$, the increase in the inflow have not been observed.

\section{Summary}

The development of mining operations at the mining of LCD coal seams alters geological and geomechanical conditions in the host rocks, leads to the activation of negative and dangerous geody- 
namic processes and phenomena: induced earthquakes, rockbursts and tectonic strokes, displacement of the ground surface, creation of new surfaces of weakening in the geological massif, change of physical and mechanical properties of rocks, etc.

This is due to several interrelated and mutually influencing factors: a) the movement of a large volume of rocks from the geological environment to the ground surface (as a consequence, the physical appearance of a large amount of worked-out space); b) changes in the stress-strain state of the LCD area; c) changes in the hydrological regime of the area; d) changes in the physical and mechanical properties of the geological environment.

The analysis of the results of modelling showed the presence of local zones with elevated stresses in the geological massif. These stresses relate to the tectonic structures and areas of mining of coal seams. The area of the Leninsky coal deposit at the time of completion of mining works potentially includes three areas of released stress intensity, the presence of which must be taken into account when assessing the safety of mining operations. Also, given the presence of hydraulic connection of Inya River with the deposit it is possible to judge about the change of the hydrological mode of the area on the basis of stress-strain state modelling. All these aspects should be taken into account in operation, liquidation and reclamation of the LCD area.

In conclusion, it should be noted that the obtained values of the SSS characteristics should be considered only as a qualitative illustration. Despite this, the results of numerical modelling of the SSS of the Leninsky coal deposit can be used as data for qualitative assessment of the impact of mine operation on the host geological environment for the conditions of Kuzbass. The obtained data could be useful in the formulation of geological and geophysical observations and geodynamic studies of the area.

Acknowledgment. This work was conducted in the framework of budgetary funding of GC RAS, adopted by the Ministry of Science and Higher Education of the Russian Federation.

\section{References}

Adushkin, V. V. (2015), Trigger seismicity of the Kuznetsk Basin, Trigger effects in geosystems. Theses of the reports of the III All-Russian seminar-meeting, p. 8-28, Institute of Dynamics of Geospheres RAS, Moscow.

Baklashov, I. V. (2004), Geomechanics. Volume 1. Fundamentals of Geomechanics, 208 pp. MSMU, Moscow.

Batugin, A. (2018), Critically Stressed Areas of Earth's Crust as Medium for Man-Caused Hazards, E3S Web Conf., VII International Scientific Conference "Problems of Complex Development of Georesources", 56, 02007, Crossref

Batugin, A. S., V. G. Klimanova (2000), Flooding of the liquidated mines as a possible cause of technogenic earthquakes in mining regions, Mining Information and Analytical Bulletin, 2, 58-61.

Batugin, A. S., et al. (2016), Tectonophysical model of fault tectonic rock burst with wing sliding Journal of Liaoning Technical University, Natural Science, 35, 561-565.

Batugina, I. M., I. M. Petukhov (1988), Geodynamic Zoning of Deposits in the Design and Operation of Mines, 166 pp. Nedra, Moscow.

Bykadorov, A. I., A. V. Chernukha, S. V. Svirko (2018), Aspects of liquidation of mines of the Prokopyevsko-Kiselevsky coal deposit, Russian Coal Journal, No. 2, 88-94, Crossref

Emanov, A. F., A. A. Emanov, E. V. Leskova, A. V. Fateev, A. Yu. Semin (2009), Seismic activation at coil mining in Kuzbass, Physical Mesomechanics, 12, No. 1, 37-43.

Emanov, A. A., A. F. Emanov, A. V. Fateev, E. V. Leskova (2018), Simultaneous Impact of Open-Pit and Underground Mining on the Subsurface and Induced Seismicity, Seismic Instruments, 54, No. 4, 479-487, Crossref

Geoinformark (2003), Coal Base of Russia, Volume 2. Coal Basins and Deposits of West Siberia (Kuznetsky, Gorlovsky, West-Siberian basins, the Deposits of the Altai Territory and the Altai Republic), 604 pp. Geoinformark, Moscow.

Gosgortechnadzor (1998), Resolution of the Gosgortechnadzor of Russia of 16.03.1998 \#13 "On the approval of the rules for the protection of structures and natural objects from the harmful influence of underground mining in coal deposits", Gosgortechnadzor, Russia.

Gvirtsman, B. Ya., N. N. Katsnelson, E. V. Boshenyatov (1977), Safe Excavation of Coal Under Water Objects, 175 pp. Nedra, Moscow.

Gvishiani, A. D., L. A. Weisberg, V. N. Tatarinov, A. I. Manevich (2018), System analysis in mining sciences and decreasing environment damage, Proceedings of the conference dedicated to the memory of Academician A. V. Kryazhimsky "System Analysis: Modeling and Management" p. 43-45, Steklov Institute of Mathematics RAS, Moscow. Crossref

Kartashev, M. P., N. P. Yesikov (1983), The study of deformations of the earth's surface on the Kuzbass polygon, Results of researches in the international 
geophysical projects "Modern Movements and Deformations of the Earth's Crust on Geodynamic Polygons" p. 102-105, Nauka, Moscow.

Kolikov, K. S., E. A. Egorova, E. V. Mazanik (2017), Geoinformation support of the forecast of dangerous natural processes during the mining of coal seams, Geoinformatics Research Papers: Proceedings of the Geophisical Center RAS, 5, No. 2, 3-12, Crossref

Kolikov, K. S., S. G. Nikitin, A. I. Manevich (2016), Analytical evaluation of the forecast methan emission recommended safety regulations, Safety of Labor in Industry, No. 8, 34-39.

Lazarevich, T. I., A. N. Polyakov (2009), Mining monitoring of seismic and geodynamic safety of Kuzbass, Mining Geomechanics and Mine Surveying: A Collection of Scientific Papers p. 252, VNIMI, $\mathrm{SPb}$.

Litvinov, A. R., K. S. Kolikov, O. G. Ishhneli (2017), Accident and injury at coal industry enterprises in 2010-2015, Bulletin of the Scientific Center for the Safety of Work in the Coal Industry, No. 2, 6-17, Crossref

Morozov, V. N., I. Yu. Kolesnikov, V. N. Tatarinov (2012), Modeling the Hazard Levels of Stress-Strain State in Structural Blocks in Nizhnekanskii Granitoid Massif for Selecting Nuclear Waste Disposal Sites, Water Resources, 39, No. 7, 756-769, Crossref

Morozov, V. N., V. N. Tatarinov, I. Yu. Kolesnikov, A. I. Manevich (2018), Modeling the Stress-Strain State in the Epicentral Zone of a Strong Earthquake in Iran (December 26, 2003, $M w=6.6$ ), Izvestiya, Physics of the Solid Earth, 54, No. 4, 602-611, Crossref

Nedra (1967), Geology of the USSR, Volume 14. Geological Description. Western Siberia, 664 pp. Nedra, Moscow.

Novikov, I. S., O. V. Cherkas, G. M. Mamedov, et al. (2013), Stages of activation and tectonic divisibility of the Kuznetsk coal basin (Southern Siberia), Geology and Geophysics, 54, No. 3, 424437, Crossref

Ovsyuchenko, A. N., E. A. Rogozhin, S. S. Novikov, et al. (2010), Paleogeological and tectonic studies of earthquake-prone areas in the south of the Kuznetsk Basin, Seismic resistant construction, Safety of Structures, No. 6, 35-45.

Panina, L. V., V. A. Zaitsev (2012), Neotectonics and geodynamics of the Kuznetsk cavity, Bulletin of the Moscow University Series 4. Geology, No. 6, 13-20, Crossref

Petukhov, I. M., I. M. Batugina (1999), Geodynamics of Soils (Second edition, revised and enlarged), 287 pp. Nedra Communications LTL, Moscow.

Popov, Yu. N. (1976), Some features of the tectonics of mine fields in the North-Eastern part of the Leninsky district of Kuzbass, Izvestiya of the Tomsk Polytechnic Institute, 236, 119-128.

Selin, K. V. (2008), Measurement of the initial stresses of the array with depth in the regions of the world, Mining Information and Analytical Bulletin, 10, $297-$ 302.

Tarasenko, I. A., A. V. Zinkov, O. V. Chudaev, A. V. Vetoshkina, I. I. Holodilov (2017), Technogenic effect of liquidation of coal mines on earth's entrails: hydrogeochemical aspect, IOP Conference Series: Earth and Environmental Science, 87, No. 4, Crossref

Yakovlev, D. V., T. I. Lazarevich, S. V. Tsirel' (2013), Natural and induced seismic activity in Kuzbass, Journal of Mining Science, 49, No. 6, 862-872, Crossref

Zhalkovsky, N. D., O. A. Kuchai, V. I. Muchnaya (1995), Seismicity and some characteristics of the stress state of the earth's crust of the Altai-Sayan region, Geology and Geophysics, 36, No. 10, 20 30.

Zubkov, A. V. (2016), The low of natural stress formation of the Earth's crust, Lithosphere, No. 5, 146 151.

Corresponding author:

A. I. Manevich, Geophysical Center of RAS, 3 Molodezhnaya St., 119296 Moscow. (ai.manevich@yandex.ru) 